\title{
Non-nutritive sweeteners: children and adolescent consumption and food sources
}

\author{
María B. Garavaglia, Student ${ }^{a}$, Vanesa Rodríguez García, B.S. ${ }^{a}$, \\ Magister María E. Zapata, B.S. ${ }^{a}$, Alicia Rovirosa, Biochemist ${ }^{a}$, Verónica González, B.S. ${ }^{b}$, \\ Florencia Flax Marcó, B.S. ${ }^{c}$ and Esteban Carmuega, M.D. ${ }^{a}$
}

\begin{abstract}
The availability of food and beverages with non-nutritive sweeteners (NNSs) has increased in recent years.

Objectives: To estimate NNSs consumption among children and adolescents in the Autonomous City of Buenos Aires, the prevalence of a daily intake higher than acceptable, and the main food and beverages contributing to it.

Material and methods: Descriptive study about the information collected in the First Food and Nutritional/Nutrition Survey of Buenos Aires City, which was conducted in 2011 and included 2664 children and adolescents aged 2-18 years. Consumption was assessed by means of a 24hour recall. NNSs content in food and beverages was obtained from nutrition facts labels. The total dietary intake for each NNSs and the adequacy to the acceptable daily intake (ADI) established by the Food and Agriculture Organization of the United Nations (FAO)/World Health Organization (WHO).
\end{abstract}

Results: Forty four percent of preschoolers, 53\% of school children, and $51 \%$ of adolescents have had food with NNSs. No child was exposed to a consumption of aspartame, acesulfameK, and sucralose higher than the ADI. Saccharin consumption was higher than the ADI in $0.3 \%$ of preschoolers while cyclamate consumption was higher than the ADI in $0.9 \%$ of school children and $0.1 \%$ of adolescents, due to the consumption of concentrated juice, to be diluted with water. Beverages provided $67 \%$ of cyclamate, $91 \%$ of acesulfameK, and $96 \%$ of aspartame. Table-top sweeteners provided $30 \%$ of cyclamate and $32 \%$ of saccharin.

Conclusion: Consumption of food and beverages with NNSs is usual among children and adolescents, mainly from beverages. Less than $1 \%$ of children are exposed to a consumption of cyclamate and saccharin higher than the ADI. Key words: non-nutritive sweeteners, food, beverages, child, adolescent.

http:/ / dx.doi.org/10.5546/ aap.2018.eng.186

María Elisa Zapata,

B.S. and Magister:

mezapata@cesni.org.ar

Funding:

None.

Conflict of interest:

None.

Received: 5-22-2017.

Accepted: 10-26-2017

To cite: Garavaglia MB, Rodríguez García V, Zapata ME, et al. Non-nutritive sweeteners: Children and adolescent consumption and food sources. Arch Argent Pediatr 2018;116(3):186-191.

\section{INTRODUCTION}

The taste for sweet is an innate human characteristic and it involves all ages, races and cultures. Throughout evolution, sweetness has played an important role in human nutrition and has helped to guide dietary behavior towards food providing essential nutrients and energy. ${ }^{1}$ The development of taste preferences starts in the womb and continues during the rest of our lives. Breast milk is the first exposure to sweet taste, ${ }^{2}$ and the predilection for the sweet reaches its maximum level in childhood and progressively decreases during adolescence and adulthood. . $^{3,4}$ Non-nutritive sweeteners (NNSs) are an option to provide sweetness to food and beverages but have a very low or null energy supply. ${ }^{5}$ However, its widespread use leads to new concerns, among which may be mentioned the disturbing effect on taste, appetite, consumption patterns, ${ }^{1}$ and safety levels, especially during childhood.

The number of food products that contain these sweeteners has been increasing for more than two decades $^{6}$ and, in recent years, they have undergone a remarkable increase because of different reasons like taste, cost, and the need to reduce sugar and energy supply in the diet given the significant prevalence of obesity. ${ }^{7}$ At present, NNSs are not only used in dietary products but also in the formula of different commonly consumed food and beverages. The greater the availability of NNSs the higher their consumption among the general population, ${ }^{8}$ and children are not alien to this reality.

Taking into account that NNSs 
are considered food additives, in order to be able to use them the Joint Food and Agriculture Organization of the United Nations (FAO)/World Health Organization (WHO) Expert Committee on Food Additives (JECFA) and the European Food Safety Authority (EFSA) undertake strict and systematic safety evaluations of food additives and regularly report the acceptable daily intake (ADI). ${ }^{9,10}$ Both in Argentina as well as in other countries of Mercosur, values established by said Committees are adopted..$^{11}$ The ADI in a NNSs is a hundredth part of an amount that, given daily, is not capable of causing harm to health. ${ }^{3}$ At an international level, it is considered a regulatory guideline that does not indicate the level of toxicity, since, in fact, it has a safety factor a hundred times higher and is expressed in $\mathrm{mg} /$ $\mathrm{kg}$ of the body weight of the subject. Although the margin of safety to surpass the ADI value is high, the estimation of consumption is made taking into account NNSs mg according to the subject's weight in $\mathrm{kg}$, so the lower the child's body weight the higher the risk for exceeding the ADI. ${ }^{8}$

No publications have been found describing sources contributing to the general diet and in a representative child and adolescent population sample in Argentina and in the Autonomous City of Buenos Aires. That is why, the objective of the this study was to estimate NNSs consumption among children and adolescents in the Autonomous City of Buenos Aires, the prevalence of a daily intake higher than acceptable, and the main contributing food groups and beverage.

\section{MATERIALS AND METHODS}

This was a descriptive, cross-sectional study. The information collected in the First Food and Nutritional/Nutrition Survey of Buenos Aires City, conducted between May and November 2011, was analyzed. A probability cluster sampling design of 2664 children and adolescents from 2 to 18 years old was used. They were divided into 3 age groups (766 preschoolers aged 2-4 years, 1067 schoolchildren aged 5-12 years, and 920 adolescents aged 13-18 years).

The information about food and beverage intake was collected by professionals with a B.S. in Nutrition trained in the technique and using the 24-hour recall interview method. Interviews were conducted at the respondents' place of residence, during weekdays, weekends, and holidays. In children younger than 13 years, the information was provided by their mothers or caregivers; in the older ones, the child him/herself answered the 24-hour recall interview, sometimes with the help of an adult. When the child ate out the day before the survey, an attempt was made to obtain the recipe used and, when this was not possible, standardized recipes were used. In the case of children attending public schools, the preparations of the school canteen menu were used and, in the case of private schools, the food service provider was contacted so that they described the menu served.

For each interview, the following information was collected and recorded: the time food was consumed, the amount and the type of food or beverage consumed (specifying the trademark), variety and taste, in the case of industrialized products. Food and beverages were coded at the time of data entry in order to link them through the code assigned to the food chemical composition table.

NNSs intake was estimated based on the information collected from the 24-hour recall interview. Five NNSs were considered because they are widely used in food products approved for use in the Argentine market: acesulfameK, aspartame, cyclamate, saccharin, and sucralose. Stevia sweetener was not taken into account because its use in food and beverages was not significant at the time of data collection given that it has recently been included as an ingredient in food products.

To obtain the amount of NNSs content in food and beverages, the information stated in nutrition facts labels was reviewed. Data on food and beverages available in supermarkets, hypermarkets, retail supermarkets, and retail grocery stores in the Autonomous City of Buenos Aires were collected. All those products in which NNSs were listed on the label were entered with the corresponding codes in the food and beverage chemical composition database, broken down by trademarks. Given that in the 24-hour recall no information was available regarding the trademark of table-top sweeteners consumed, all of them were considered as cyclamate and saccharin because, at the time of the survey, it was the most frequent combination of table-top sweeteners available in the market. In the case of powder table-top sweeteners, the serving size considered was $0.8 \mathrm{~g}$ per packet while in liquid presentations, the serving size was $0.4 \mathrm{~mL}$ per every 8 drops used. For powder and concentrated drinks to be diluted, reconstitution was assumed following package instructions, unless the respondent stated another level of dilution. 
Based on the amount of food and beverages recorded in the 24-hour recall interview and on the content of each type of NNS every $100 \mathrm{~g}$ of food or $100 \mathrm{~mL}$ of beverage, the total intake of each NNS was estimated, stated in mg/day. Then it was divided by the body weight in kilograms and the quantity consumed by kilogram of weight per day ( $\mathrm{mg} / \mathrm{kg} /$ day) was obtained. Children and adolescents' weight was obtained by anthropometric measurement using a portable OMROM HB-500INT Body Composition Monitor with scale, with an accuracy of $0.1 \mathrm{~kg}$ and a maximum weight of $150 \mathrm{~kg}$.

In all the cases, weight was measured with the subject wearing the minimum clothes possible; then, the weight of clothes they were wearing was subtracted.

To evaluate ADI adequacy, the total intake of each NNS ( $\mathrm{mg} / \mathrm{kg} /$ day) was compared to the value recommended by the JECFA, ${ }^{9}$ which has been incorporated into the Argentine Food Code (Código Alimentario Argentino) ${ }^{12}$ as a reference to regulate the use of food additives. For acesulfameK, the ADI was $15 \mathrm{mg} / \mathrm{kg} /$ day; for aspartame, $40 \mathrm{mg} / \mathrm{kg} /$ day; for cyclamate, $11 \mathrm{mg} / \mathrm{kg} /$ day; for saccharin, $2.5 \mathrm{mg} / \mathrm{kg} /$ day; and for sucralose, $15 \mathrm{mg} / \mathrm{kg} /$ day.

The following parameters were estimated: descriptive statistics in the NNSs intake among consumers, the percentage of consumers in each NNS, and the percentage of subjects with an intake higher than the ADI. The contribution of each type of NNS was estimated by group, subgroup, and category of food and beverages.

The statistical analysis was done considering the sample weight; measures of position, dispersion, and percentages were calculated.

\section{Ethical considerations}

All aspects related to the development of this project have been conducted in accordance with valid national and international standards. An informed consent was signed by responsible adults or caregivers of participating children and adolescents.

\section{RESULTS}

Out of the 2664 surveyed children and adolescents, $51 \%$ had consumed food or beverages containing some NNSs. Table 1 shows the proportion of children and adolescents that consumed food and beverages with each type of NNS. The most consumed NNSs were aspartame and acesulfameK. Considering that more than one type of NNSs might be simultaneously present in a food or beverage, $34 \%$ of preschoolers consumed between 1 and 2 types of different NNSs and $10 \%$ more than 2 types. Among schoolchildren, these values increased to $40 \%$ and $13 \%$, and among adolescents, to $36 \%$ and $15 \%$, respectively. In spite of cyclamate being the NNSs less included in a diet, it surpassed the ADI in $1.1 \%$ of preschoolers, $0.9 \%$ of schoolchildren, and $0.1 \%$ of adolescents, mainly because of its content in concentrated juice to dilute with water and children who exceeded the ADI had consumed more than 1 liter of diluted concentrated juice per day. As far as preschoolers, $0.3 \%$ had a consumption of saccharin higher than the ADI. The level of consumption of the remaining NNSs was below the ADI for all the population evaluated.

AcesulfameK, aspartame, and sucralose intake average and median values were far from the ADI, while for cyclamate and saccharin the distance was shorter, especially in younger children (Table 2).

Beverages were the main source of NNSs in children's and adolescents' diets: aspartame 95\%, acesulfameK $90 \%$, cyclamate $69 \%$, saccharin $66 \%$, and sucralose $72 \%$. Aspartame was an ingredient in powder juice, diet powder juice, and diet soft drinks. AcesulfameK, in powder juice, diet soft drinks, diet powder juice, and flavored waters. Cyclamate, in concentrated juice. Saccharin, in concentrated juice, powder juice, and soft drinks. And sucralose, in canned or bottled juice and flavored waters (Table 3).

The second source in the diet were table-top sweeteners, consumed by $3.2 \%$ of the evaluated population; they supplied a third part of saccharin and cyclamate consumption. Gelatin, yogurt, milk desserts, sweets, and candies contributed with a small part to total intake (Table 3).

The proportion of NNSs as an ingredient in powder juice, concentrated juice, canned or bottled juice, candies, sweets, and gelatin and dessert

TABLE 1. Proportion of children and adolescents consuming each non-nutritive sweetener by age group (\%)

\begin{tabular}{lccc}
\hline & $\begin{array}{c}\text { 2 to 4 years old } \\
\mathbf{N = 7 6 6}\end{array}$ & $\begin{array}{c}\mathbf{5} \text { to } \mathbf{1 2} \text { years old } \\
\mathbf{N = 1 0 6 7}\end{array}$ & $\begin{array}{c}\text { 13 to 18 years old } \\
\mathbf{N = 9 2 0}\end{array}$ \\
\hline AcesulfameK & 38 & 46 & 44 \\
Aspartame & 40 & 48 & 45 \\
Cyclamate & 3 & 6 & 8 \\
Saccharin & 11 & 11 & 15 \\
Sucralose & 8 & 14 & 12 \\
\hline
\end{tabular}


powder decreased as age increased, while the contribution of flavored waters, diet soft drinks, and table-top sweeteners increased with age (Table 3).

\section{DISCUSSION}

Our study shows that NNSs intake is widespread among children and adolescents in the Autonomous City of Buenos Aires, mainly in relation to beverages that do not have the low calorie feature highlighted in their labels although they comply with the Argentine Food Code to include in the main label (product denomination) the identification as recommendation diet food or beverage or for special diets because a NNS is one of the ingredients. ${ }^{11}$ Powder juice, concentrated juice, canned or bottled juice, flavored waters,

TABLE 2. Distribution of the consumption of non-nutritive sweeteners based on the age group (mg/kg/day)

\begin{tabular}{|c|c|c|c|c|c|c|}
\hline & $A D I$ & Mean & SD & $25^{\text {th }}$ percentile & Median & $75^{\text {th }}$ percentile \\
\hline AcesulfameK & 15 & & & & & \\
\hline 2 to 4 years old & & 1.9 & 1.5 & 0.8 & 1.4 & 2.7 \\
\hline 5 to 12 years old & & 1.4 & 1.5 & 0.5 & 1.0 & 1.7 \\
\hline 13 to 18 years old & & 1.0 & 1.1 & 0.3 & 0.7 & 1.3 \\
\hline Aspartame & 40 & & & & & \\
\hline 2 to 4 years old & & 6.8 & 5.4 & 2.9 & 5.5 & 9.3 \\
\hline 5 to 12 years old & & 4.2 & 4 & 1.7 & 3.2 & 5.3 \\
\hline 13 to 18 years old & & 2.9 & 2.4 & 1.3 & 2.2 & 4.1 \\
\hline Cyclamate & 11 & & & & & \\
\hline 2 to 4 years old & & 11.6 & 12.9 & 3.5 & 5.3 & 19.4 \\
\hline 5 to 12 years old & & 4.3 & 4.9 & 1.1 & 2.1 & 5.4 \\
\hline 13 to 18 years old & & 2.0 & 2.1 & 0.8 & 1.3 & 2.1 \\
\hline Saccharin & 2.5 & & & & & \\
\hline 2 to 4 years old & & 1.0 & 1.3 & 0.2 & 0.5 & 1.1 \\
\hline 5 to 12 years old & & 0.3 & 0.7 & 0.0 & 0.1 & 0.4 \\
\hline 13 to 18 years old & & 0.4 & 0.4 & 0.1 & 0.3 & 0.5 \\
\hline Sucralose & 15 & & & & & \\
\hline 2 to 4 years old & & 0.3 & 0.4 & 0.1 & 0.1 & 0.6 \\
\hline 5 to 12 years old & & 0.6 & 0.6 & 0.0 & 0.3 & 0.8 \\
\hline 13 to 18 years old & & 0.1 & 0.1 & 0.0 & 0.1 & 0.2 \\
\hline
\end{tabular}

ADI: acceptable daily intake; SD: standard deviation.

Note: Values were estimated in consumers of every type of NNS.

TABLE 3. Non-nutritive sweetener intake by category of food and beverage, total and by age group (\%)

\begin{tabular}{|c|c|c|c|c|c|c|c|c|c|c|c|c|c|c|c|c|c|c|c|c|}
\hline \multirow[b]{2}{*}{ Age (years old) } & \multicolumn{4}{|c|}{ AcesulfameK } & \multicolumn{4}{|c|}{ Aspartame } & \multicolumn{4}{|c|}{ Cyclamate } & \multicolumn{4}{|c|}{ Saccharin } & \multicolumn{4}{|c|}{ Sucralose } \\
\hline & $\begin{array}{c}2 \\
\text { to } 4 \\
\end{array}$ & $\begin{array}{c}5 \\
\text { to } 12 \\
\end{array}$ & $\begin{array}{c}13 \\
\text { to } 18 \\
\end{array}$ & Total & $\begin{array}{c}2 \\
\text { to } 4 \\
\end{array}$ & $\begin{array}{c}5 \\
\text { to } 12 \\
\end{array}$ & $\begin{array}{c}13 \\
\text { to } 18 \\
\end{array}$ & Total & $\begin{array}{c}2 \\
\text { to } 4\end{array}$ & $\begin{array}{c}5 \\
\text { to } 12 \\
\end{array}$ & $\begin{array}{c}13 \\
\text { to } 18 \\
\end{array}$ & Total & $\begin{array}{c}2 \\
\text { to } 4 \\
\end{array}$ & $\begin{array}{c}5 \\
\text { to } 12 \\
\end{array}$ & $\begin{array}{c}13 \\
\text { to } 18 \\
\end{array}$ & & $\begin{array}{c}2 \\
\text { to } 4 \\
\end{array}$ & $\begin{array}{c}5 \\
\text { to } 12 \\
\end{array}$ & $\begin{array}{c}13 \\
\text { to } 18 \\
\end{array}$ & Total \\
\hline avored $\mathbf{w}$ & 1.8 & 9.1 & 10.9 & 7.3 & 0.2 & 1.9 & 1.5 & 1.2 & 0.0 & 0.0 & 0.0 & 0.0 & 0.0 & 0.0 & 0.0 & 0.0 & 3.3 & 13.1 & 27.2 & 14.5 \\
\hline oft drinks & 0.0 & 0.0 & 0.0 & & 0.1 & 0.3 & 0.1 & 0.2 & 0.0 & 0.0 & 0.0 & 0.0 & 3 & 20.3 & 9.5 & 12.0 & 0.0 & 6.6 & 12.7 & 6.4 \\
\hline Diet soft drinks & 14.6 & 25.5 & 28.6 & 22.9 & 4.4 & 9.2 & 10.3 & 8.0 & 0.0 & 0.0 & 0.0 & 0.0 & 0.0 & 0.0 & 0.0 & 0.0 & 0.0 & 0.0 & 0.0 & 0.0 \\
\hline Powder juice & 59.9 & 39.1 & 42.6 & 47.2 & 63.0 & 46.8 & 52.9 & 54.3 & 0.0 & 0.0 & 0.0 & 0.0 & 35.6 & 17.2 & 19.7 & 24.2 & 0.0 & 0.0 & 0.0 & 0.0 \\
\hline iet powder ju & 12.7 & 14.9 & 13.0 & 13.5 & 26.5 & 37.3 & 33.5 & 32.4 & 0.0 & 0.0 & 0 & 0.0 & 0.0 & 0.0 & 0.0 & 0.0 & 0.0 & 0.0 & .0 & .0 \\
\hline Concentrated $\mathrm{j}$ & 0.0 & 0.0 & 0.0 & 0.0 & 0.0 & 0.0 & 0.0 & 0.0 & 83.2 & 72.7 & 50.2 & 68.7 & 39.0 & 32.0 & 20.2 & 30.4 & 0.0 & 0.0 & 0.0 & 0.0 \\
\hline & 0.0 & 0.0 & 0.0 & & 0.0 & 0.0 & 0.0 & 0.0 & 0.0 & 0.0 & 0.0 & & 0.0 & 0.0 & 0.0 & 0.0 & 74.4 & 22.9 & 26.6 & 41.3 \\
\hline & 0.1 & 0.8 & 0.0 & & 0.1 & 0.0 & 0.0 & & 0.0 & 0.0 & 0.0 & & 0.0 & 0.0 & 0.0 & & 0.0 & 24.0 & 0.0 & 8.0 \\
\hline O1 & s 0.0 & 0.2 & 0.2 & 0.1 & 0.0 & 0.0 & 0.1 & 0.0 & 0.0 & 0.0 & 0.0 & 0.0 & 0.0 & 0.0 & 0.0 & 0.0 & 0.0 & 3.2 & 2.5 & 1.9 \\
\hline $\begin{array}{l}\text { andies, sweets, } \\
\text { elatin and } \\
\text { essert powders }\end{array}$ & 9.0 & 6.3 & 2.6 & & 5.3 & 4.1 & 1.2 & 3.5 & 0.4 & 0.2 & 0.5 & 0.4 & 0.6 & 0.7 & 0.8 & 0.7 & 7.7 & 4.6 & 5.6 & 6.0 \\
\hline & 1.7 & 4.0 & 2.3 & 2.6 & 0.0 & 0.3 & 0.3 & 0.2 & 1.7 & 0.4 & 0.2 & & 1.0 & 0.2 & 0.1 & 0.5 & 14.5 & 25.7 & 25.2 & 21.8 \\
\hline Table-top sweeteners & 0.0 & 0.0 & 0.0 & 0.0 & 0.0 & 0.0 & 0.0 & 0.0 & 14.8 & 26.7 & 49.1 & 30.2 & 17.5 & 29.6 & 49.7 & 32.2 & 0.0 & 0.0 & 0.0 & 0.0 \\
\hline
\end{tabular}


and soft drinks are among these products. The consumption of juice and soft drinks has duplicated in the last 20 years in Argentina ${ }^{13}$ and three fourths of fluid intake among children and adolescents is related to drinking beverages with and without sugar, ${ }^{14}$ which accounts for these being the main NNSs source of the diet among the child and adolescent population. Additionally and given that NNSs consumption is evaluated in milligrams per kilogram of body weight, younger children have a higher intake compared to older children as a consequence of a similar intake volume of beverages containing them.

In the last 10 years, various authors evaluated NNSs intake in the general population, ${ }^{15-19}$ in Denmark, Sweden, and Italy, among other countries. Some showed that, in the child population, cyclamate and saccharin ADI has been exceeded ${ }^{15,16}$ in relation to the consumption of beverages and table-top sweeteners, while in others no evidence of risk was found. ${ }^{17-19}$ In Argentina and Latin America, there are studies estimating the consumption related to certain food sources or in specific age groups. ${ }^{7,8,20-22}$ Results varied, both with cyclamate values higher than the $\mathrm{ADI}^{8,21}$ as well as with cyclamate, saccharin, and sucralose values that did not surpass the ADI. ${ }^{22}$ Studies conducted in Argentina ${ }^{8}$ and Chile, ${ }^{7,20-22}$ showed data similar to the ones found in this study: more than half of the children and adolescents habitually have some type of sweetener with or without a condition thus requiring it; beverages are the main source and cyclamate consumption is well beyond the ADI in approximately $1 \%$ of the evaluated population. However, this is the first study analyzing the data about consumption in a representative child and adolescent population sample in the Autonomous City of Buenos Aires.

One of the limitations of the study is that a 24-hour recall interview was used as a source to obtain information about the intake. This is a good method to estimate the mean intake but might underestimate the percentage of consumers. Since only recall was available, the adjustment of the usual NNSs intake could not be made; therefore, the prevalence of excessive consumption could have been overestimated. Hence, it is necessary to conduct studies taking into account intake in more than one day. In spite of the low proportion of children taking table-top sweeteners (3.3\%), the limitation is the lack of record about the type or the trademark of the table-top sweetener used; consequently, it had to be assumed to estimate the consumption of a cyclamate and saccharin mix since it is the most frequent combination found in the Argentine market.

It is very important to determine NNSs consumption and the food where they are found, considering educational campaigns, public policies, and regulatory processes because it is usual to consider that NNSs are only present in diet, light or low calorie products. It is also important that the society identifies NNSs dietary sources even in the products in which their supply goes unnoticed, especially at early ages. Besides, the exposure to sweet taste during childhood, its impact on the molding of food preferences, and the physiological consequences are important areas for research ${ }^{1}$ because of the role that consumption of food plays in the increase of the prevalence of excessive body weight from an early age.

\section{CONCLUSION}

The consumption of food products with NNSs is usual among children and adolescents in the Autonomous City of Buenos Aires. The main source of NNSs are beverages. The ADI for cyclamate and saccharin was exceeded, and it was related to the high consumption of juice. No child or adolescent exceeded the ADI of the other NNSs evaluated.

\section{REFERENCES}

1. Drewnowski A, Mennella JA, Johnson SL, et al. Sweetness and food preference. J Nutr 2012;142(6):1142S-8S.

2. Bellisle F, Drewnowski A, Anderson GH, et al. Sweetness, satiation, and satiety. J Nutr 2012;142(6):1149S-54S.

3. Serra-Majem L, Riobó Serván P, Belmonte Cortés S, et al. Chinchón declaration; decalogue on low-and no-calorie sweeteners (LNCS). Nutr Hosp 2014;29(4):719-34.

4. Varela-Moreiras G. The sweet taste across the life stages. Nutr Hosp 2014;29(4):719-34.

5. Shankar P, Ahuja S, Sriram K. Non-nutritive sweeteners: review and update. Nutrition 2013;29(11-12):1293-9.

6. Bertorelli AM, Czarnowski-Hill JV. Review of present and future use of nonnutritive sweeteners. Diabetes Educ 1990;16(5):415-22.

7. Duran Aguero S, Oñate G, Haro Rivera P. Consumo de edulcorantes no nutritivos y estado nutricional de escolares de 10-16 años. Arch Argent Pediatr 2014;112(3):207-14.

8. Cagnasso CE, López LB, Valencia ME. Edulcorantes no nutritivos en bebidas sin alcohol: estimación de la ingesta diaria en niños y adolescentes. Arch Argent Pediatr 2007;105(6):517-21.

9. WHO. Application of risk analysis to food standards issues. Report of the JointFAO/WHOExpertConsultation. Geneva; 1995. [Accessed on: October $30^{\text {th }}, 2017$ ]. Available at: http: / / www.fao.org/docrep/008/ae922e/ae922e00.htm.

10. WHO: General Standard For Food Additives. Codex Stan 192-1995. Codex Alimentarius International Food Standards. 2017. [Accessed on: October $30^{\text {th }}, 2017$ ]. Available at: http: / / www.fao.org/gsfaonline/docs/CXS_192e.pdf. 
11. ANMAT. Alimentos de Régimen o Dietéticos. Artículos: 1339 al 1390. Código Alimentario Argentino. [Accessed on: October $30^{\text {th }}$, 2017]. Available at: http: / / www.anmat.gov. ar/alimentos/codigoa/CAPITULO_XVII.pdf.

12. ANMAT. Alimentos de régimen o dietéticos. Artículo 1347, Res 1542, 12.09.90. In: Código Alimentario Argentino. [Accessed on:October30 ${ }^{\text {th }}$, 2017]. Available at:http: / / www. anmat.gov.ar/alimentos/codigoa/CAPITULO_XVII.pdf.

13. Zapata ME, Rovirosa A, Carmuega E. Cambios en el patrón de consumo de alimentos y bebidas en Argentina, 19962013. Salud Colect 2016;12(4):473-86.

14. Zapata ME. Patrón de consumo de bebidas en Argentina: resultados de los estudios Hidratar I e Hidratar II. In: Carmuega E, edit. Hidratación saludable en la infancia. Buenos Aires: CESNI; 2015.Pages 143-58.

15. Ilbäck NG, Alzin M, Jahrl S, et al. Estimated intake of the artificial sweeteners acesulfame-K, aspartame, cyclamate and saccharin in a group of Swedish diabetics. Food Addit Contam 2003;20(2):99-114.

16. Leth $T$, Jensen $U$, Fagt $S$, et al. Estimated intake of intense sweeteners from non-alcoholic beverages in Denmark, 2005. Food Addit Contam Part A Chem Anal Control Expo Risk Assess 2008;25(6):662-8.
17. Arcella D, Le Donne C, Piccinelli R, et al. Dietary estimated intake of intense sweeteners by Italian teenagers. Present levels and projections derived from the INRAN-RM-2001 food survery. Food Chem Toxicol 2004;42(4):677-85.

18. Ha MS, Ha SD, Choi SH, et al Assessment of exposure of Korean consumers to acesulfame $\mathrm{K}$ and sucralose using a stepwise approach. Int J Food Sci Nutr 2013;64(6):715-23.

19. Dewinter L, Casteels K, Corthouts K, et al. Dietary intake of non-nutritive sweeteners in type 1 diabetes mellitus children. Food Addit Contam Part A Chem Anal Control Expo Risk Assess 2016;33(1):19-26.

20. Durán Agüero S, Record Cornwall J, Encina Vega C, et al. Consumo de edulcorantes no nutritivos en bebidas carbonatadas en estudiantes universitarios de algunos países de Latinoamérica. Nutr Hosp 2015;31(2):959-65.

21. Lux G, Visintin C. Consumo de ciclamato en niños y adolescentes diabéticosque asisten a dos hospitales públicos de la ciudad de Rosario. Invenio 2011;14(27):113-33.

22. Durán Agüero S, Quijada M, Silva L, et al. Niveles de ingesta diaria de edulcorantes no nutritivos en escolares de la región de Valparaíso. Rev Chil Nutr 2011;38(4):444-9. 